\title{
DAPT Enhances the Apoptosis of Human Tongue Carcinoma Cells
}

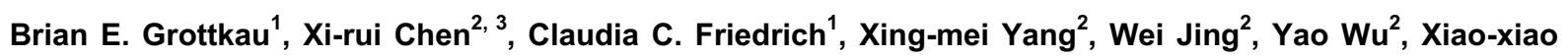 \\ Cai $^{2}$, Yu-rong Liu ${ }^{2}$, Yuan-ding Huang ${ }^{2,4 *}$, Yun-feng Lin ${ }^{1,2 *}$ \\ ${ }^{1}$ Department of Orthopaedic Surgery, MassGeneral Hospital for Children and the Pediatric Orthopaedic Laboratory for \\ Tissue Engineering, Harvard Medical School, Boston, USA \\ ${ }^{2}$ State Key Laboratory of Oral Diseases, Sichuan University, Chengdu, China \\ ${ }^{3}$ Institute of Technology, University of Toronto, Ontario, Canada \\ ${ }^{4}$ Department of Oral and Maxillofacial Surgery, Beijing Friendship Hospital affiliated to Capital Medicine University, \\ Beijing, China
}

\begin{abstract}
Brian E. Grottkau, Xi-rui Chen, Claudia C. Friedrich, Xing-mei Yang, Wei Jing, Yao Wu, Xiao-xiao Cai, Yu-rong Liu, Yuan-ding Huang, Yun-feng Lin. DAPT Enhances the Apoptosis of Human Tongue Carcinoma Cells. International Journal of Oral Science, 1(2): 81-89, 2009
\end{abstract}

Aim To investigate the effect of DAPT $(\gamma$-secretase inhibitor) on the growth of human tongue carcinoma cells and to determine the molecular mechanism to enable the potential application of DAPT to the treatment of tongue carcinoma.

Methodology Human tongue carcinoma Tca8113 cells were cultured with DAPT. Cell growth was determined using Indigotic Reduction method. The cell cycle and apoptosis were analyzed by flow cytometry. Real-time
PCR and Immuno-Fluorescence (IF) were employed to determine the intracellular expression levels.

Results DAPT inhibited the growth of human tongue carcinoma Tca8113 cells by inducing $\mathrm{G}_{0}-\mathrm{G}_{1}$ cell cycle arrest and apoptosis. The mRNA levels of Hairy/Enhancer of Split-1 (Hes-1), a target of Notch activation, were reduced by DAPT in a dose-dependent manner. Coincident with this observation, DAPT induced a dose-dependent promotion of constitutive Caspase- 3 in Tca8113 cells.

Conclusion DAPT may have a therapeutic value for human tongue carcinoma. Moreover, the effects of DAPT in tumor inhibition may arise partly via the modulation of Notch-1 and Caspase-3.

Keywords DAPT, human tongue carcinoma cells, Notch, Caspase-3

Document code: A CLC number: Q255 Received Dec. 1, 2008; Revision accepted Jan. 14, 2009

\section{Introduction}

Notch signalling is known as an evolutionarily conserved mechanism involved in cell proliferation, differentiation and apoptosis (Katoh and Katoh, 2007; Hansson et al., 2004). Nowadays, it has been studied as an important factor in multiple contexts such as organ development (Hansson et al., 2004), tissue regeneration (Lovschall et al., 2005) and carcinogenesis (Liao et al., 2007; Maliekal et al., 2008; Talora et al., 2008). Briefly, it serves a fundamental role in many cell fate decisions, maintaining the balance between cell differentiation and proliferation (Katoh and Katoh, 2007).

Notch signalling is initiated through interactions between a receptor and one of its several ligands between neighbouring cells. In mammalian cells, there are four Notch receptors (Notch-1, Notch-2, Notch-3 and Notch-4) and five type I transmembrane ligands (Jagged-1, Jagged-2, Delta- like-1, Delta-like-3, and Delta-like-4). Although similar, 
the four receptors show differences in structure that are likely to be responsible for their different expression patterns (Baldi et al., 2004) and unique functions (Artavanis-Tsakonas et al., 1999). Once bound with a ligand, a Notch receptor is cleaved away first by a disintigrin and metalloprotease, TACE (tumor necrosis factor- $\alpha$ (TNF- $\alpha$ ) converting enzyme) and then by a $\gamma$-secretase complex that contains the membrane proteins, presenilin and nicastrin. The second cleavage event releases the soluble intracellular fragment of Notch, called NICD (Notch intracellular domain) (Baron et al., 2003).

NICD translocates to the nucleus and binds a CCAAT-binding protein, CBF-1 (also called CSL or RBPJк). As a consequence, NICD displaces the repressor complex of CBF-1/SMRT-sin3-HDAC-1 and recruits nuclear co-activators, such as MAML1 (mastermind-like 1) (Mitsiadis et al., 2005; Kadesch et al., 2004) and histone acetyltransferases, converting CBF-1 into a transcriptional activator. Notch activation through CBF-1-NICD interactions can then activate transcription of various target genes, including Hes (Hairy/Enhancer of Split) (ArtavanisTsakonas et al., 1999), HERP (Hes-related repressor protein) (Iso et al., 2001; Iso et al., 2003), NF-кB

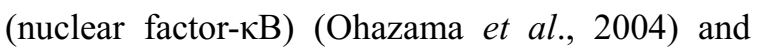
PPAR (peroxisome-proliferator-activated receptor) (McKenzie and Sabin, 2005) families, and genes of cell cycle regulators such as p21CIP1/WAF1 and cyclin D (Joshi et al., 2008). The set of directly and indirectly Notch-regulated genes and proteins is probably very large and context dependent. Thus, DAPT (N-[N-(3,5-difluorophenacetyl)-L-alanyl]-Sphenylglycine t-butyl ester), an inhibitor of $\boldsymbol{\gamma}$-secretase (GSI) can efficiently block the $\gamma$-secretase complex and as a consequence, efficiently prevents Notch signaling (Cheng and Kopan, 2005).

Aberrant Notch signalling can be detected in a wide variety of human tumors, such as mammary carcinoma and leukemia (Imatani and Callahan, 2000; Callahan and Egan, 2004; Grabher et al., 2006). Notch can either suppress or promote tumors depending on the cell type and context (Fan et al., 2004; Mansour et al., 2006; Vacca et al., 2006; Zhu et al., 2006; O'Neill et al., 2007). Not only are there multiple Notch receptors and ligands (each with a unique expression pattern), but the large number of target genes and potential cross-talk between Notch and other signalling cascades further complicate the system. Given the complexity of Notch signalling, it is understandably difficult to predict the outcome of Notch activation. Much more remains to be unraveled about the cross-talk between Notch signalling and other signalling pathways, which will provide explanations for some of the elusive effects of the cascade.

In the present study, we found for the first time that DAPT, a potent $\gamma$-secretase inhibitor, could strongly suppress proliferation of Tca8113 cells by inducing cell cycle arrest and apoptosis. One plausible mechanism of this growth inhibition might involve down-regulation of Notch-1 and Caspase-3 signalling, suggesting an across-talk between them in Tca8113 cells. Our findings may provide important clues to aid our understanding of the pathogenesis and modulation of the state of oral squamous cell carcinomas.

\section{Materials and methods}

\section{Cancer cell line}

Human tongue carcinoma cell line Tca8113 (State Key Laboratory of Oral Diseases, Sichuan University, China) was cultured in $\alpha$-MEM, supplemented with $10 \%$ fetal bovine serum (FBS).

\section{DAPT treatment of human tongue carcinoma cell line Tca8113}

DAPT (Sigma-Aldrich, USA) was dissolved in $100 \%$ dimethylsulphoxide (DMSO) to make a stock solution of $1 \mathrm{mmol} / \mathrm{L}$, which was then diluted in culture medium to obtain the desired concentrations of $1,2,5$ and $10 \mu \mathrm{mol} / \mathrm{L}$. Control cells were treated with $0.5 \%$ DMSO for 48 hours.

\section{Analysis of cell growth and $G_{0}-G_{1}$ cell cycle arrest in vitro}

The in vitro growth rate of Tca8113 cells treated with DAPT was measured with the SunBio ${ }^{\mathrm{TM}}$ Am-Blue Cell proliferation and activation detection kit $\left(\mathrm{SBO}^{\mathrm{TM}}\right.$, China). Briefly, Tca8113 cells were seeded in 96-well plates. On the day of harvest, $10 \mu \mathrm{L}$ of SunBio ${ }^{\mathrm{TM}}$ Am-Blue were added to 
each well. Plates were incubated in a cell incubator at $37^{\circ} \mathrm{C}$ for 4 hours. When the medium color changed from blue into pink, the absorbance was measured (excitation $540 \mathrm{~nm}$, emission $595 \mathrm{~nm}$ ) using a HTS 7000 Plus Bio Assay Reader (PERKIN ELMER, PE Co., USA). Cells for flow cytometry analysis were cultured in medium-sized culture flasks. The culture medium was replaced with fresh medium when the cells were $80 \%$ confluent and then cells were exposed to various concentrations of DAPT for 48 hours. Later, adherent and floating cells were pooled, washed with phosphate buffered saline (PBS), then fixed in ice-cold $70 \%$ ethanol, and stored at $-20^{\circ} \mathrm{C}$. Prior to analysis, cells were washed and resuspended at $1 \times 10^{6}$ cells $/ \mathrm{mL}$ in PBS buffer, and incubated with $0.1 \mathrm{mg} / \mathrm{mL}$ RNase A and $40 \mu \mathrm{g} / \mathrm{mL} 4$ ',6-diamidino2-pheny-lindole dihydrochloride (DAPI; Roche, Switzerland) at $37^{\circ} \mathrm{C}$ for 30 minutes. Samples were analyzed using a fluorescence activated cell sorting (FACS) scanner (Becton Dickinson, USA).

\section{Real-time polymerase chain reaction detection of Notch-1, Hes-1, Caspase-3, Bcl-1}

Total RNA from Tca8113 cells was extracted using Total Tissue/cell RNA Extraction Kits (Watson, China), according to the manufacturer's protocol. RNA was reversely transcribed into cDNA in a $10 \mu \mathrm{L}$ reverse transcription system (Takara, Japan) according to the manufacturer's instructions. To establish the standard curve of home-keeper or target genes, cDNA samples were amplified using a reverse transcriptase polymerase chain reaction (RT-PCR) kit (Tiangen, China). Primers used in the present study were designed using the PrimerBLAST tool from the NCBI website online (http: //www.ncbi.nlm.nih.gov/tools/primerblast/index.
cgi?LINK_LOC=BlastHomeAd), based on a human mRNA sequence database. The primer sequences used to amplify these genes are shown in Table 1. All PCR products were resolved on a $2 \%$ agarose gel and underwent agarose electrophoresis, generating bright and condensed target bands. Expression of certain genes in ASCs was then quantified by real-time PCR using the $\mathrm{SYBR}^{\circledR}$ Premix Ex $\mathrm{Taq}^{\mathrm{TM}}$ (Perfect Real Time) kit (Takara, Japan). Reactions were carried out on an ABI 7300 system (ABI, USA), under the following conditions: cDNA was denatured for 10 seconds at $95^{\circ} \mathrm{C}$, followed by 40 cycles, consisting of 5 seconds at $95^{\circ} \mathrm{C}$ and 34 seconds at $60^{\circ} \mathrm{C}$. For each reaction, a melting curve was generated to test for primer dimmer formation and false priming. Reactions were carried out on an ABI 7300 system (ABI, USA), under the following conditions: relative quantification of target genes was carried out according to the two-standard-curve method (Jorgensen and Leser, 2007).

\section{Immunofluorescence staining}

Tca8113 cells cultured in ordinary medium were seeded on glass coverslips in six-well plates before staining. After 48 hours of incubation with $0.5 \%$ DMSO-added medium or DAPT-added medium, cells were washed briefly with PBS, fixed in cold acetone for 10 minutes at room temperature, and then permeabilized and blocked in $5 \%$ bovine serum albumin (BSA) for 30 minutes at room temperature. Slips were subsequently incubated overnight at $4^{\circ} \mathrm{C}$ with rabbit polyclonal antibodies against Caspase-3 (AbCam, USA). Sequentially, slides were incubated with secondary antibodies conjugated to fluorescein isothiocyanate (FITC; Pierce, USA), and nuclei were stained with DAPI. After rinsing in PBS,

Table 1 Primers used in the present study were designed using the Primer-BLAST tool from the NCBI website online based on a human mRNA sequence database

\begin{tabular}{lcllc}
\hline Genes & NM & \multicolumn{1}{c}{ Forward (5'-3') } & Reverse (5'-3') & $\begin{array}{c}\text { Product } \\
(\mathrm{bp})\end{array}$ \\
\hline Notch-1 & 017617.3 & TACAAGTGCAACTGCCTGCT & TCATAGTCCTCGGATTGCCT & 116 \\
Hes-1 & 005524.2 & TCAACACGACACCGGATAAA & TCAGCTGGCTCAGACTTTCA & 111 \\
Bcl-1 & 053056.2 & CGTGGCCTCTAAGATGAAGG & CCACTTGAGCTTGTTCACCA & 127 \\
c-Myc & 002467.3 & TAGTGGAAAACCAGCAGCCT & TCGTCGCAGTAGAAATACGG & 109 \\
Caspase-3 & 004346.3 & CCTCTTCCCCCATTCTCAT & GAGTCCATTGATTCGCTTCC & 119 \\
GAPDH & 002046.3 & CCGCATCTTCTTTTGCGT & AGTTAAAAGCAGCCCTGGTG & 120 \\
\hline
\end{tabular}


cells were observed and imaged using a fluorescence microscope (Leica, DMi 6000 B, Germany).

\section{Statistic analysis}

Data were summarized as means values \pm SD $(\bar{\chi} \pm s)$. Statistical differences were determined using ANOVA or Student's $t$-test. A $P<0.05$ represented a statistically significant difference.

\section{Results}

\section{DAPT inhibits the growth of Tca8113 cells}

The treatment of Tca8113 cells with DAPT led to cell growth inhibition. DMSO, which was used for dissolving DAPT, served as the control. DAPT dose-dependently $(1,2,5$ and $10 \mu \mathrm{mol} / \mathrm{L})$ inhibited the cell growth of Tca8113 (Figure 1). Inhibition of cell growth observed by Indigotic Reduction method could also be attributable to the induction of cell cycle arrest and/or apoptosis. Therefore, we further explored whether the inhibition of cell growth was also accompanied by the induction of cell cycle arrest and/or apoptosis induced by DAPT.

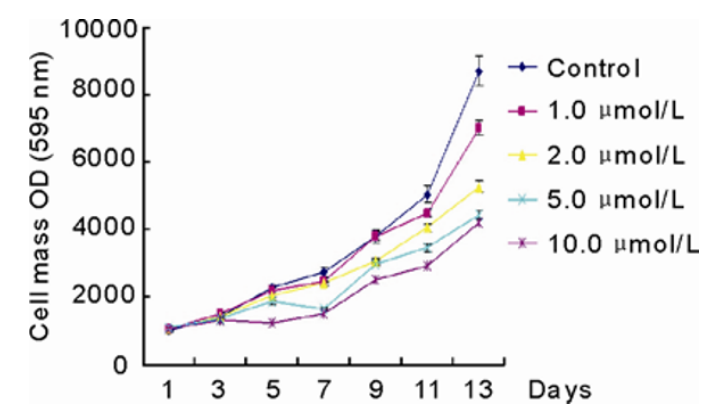

Figure 1 Effect of DAPT on Tca8113 proliferation Cells were cultured with various concentrations of DAPT ranging from 0 to $10 \mu \mathrm{mol} / \mathrm{L}$ for 48 hours, and then cell growth was determined using the Indigotic Reduction method. Three independent experiments were carried out and each was performed in triplicate in 96-well plates.

\section{DAPT induces $G_{0}-G_{1}$ arrest and apoptosis in Tca8113 cells}

To examine whether the growth inhibitory effect of DAPT was related to the induction of cell cycle arrest or an apoptotic process in Tca8113 cells, we used flow cytometry to analyze the cell cycle. DAPT dose-dependently induced $\mathrm{G}_{0}-\mathrm{G}_{1}$ arrest at concentrations ranging from 1 to $5.0 \mu \mathrm{mol} / \mathrm{L}$ for 48 hours (Figure 2). To further clarify whether the growth inhibitory effect of DAPT was associated with apoptosis, flow cytometry was also used to analyze apoptosis. DAPT-treated cells demonstrated a sub- $\mathrm{G}_{1}\left(\mathrm{M}_{1}\right)$ DNA in a dose-dependent manner. At $1 \mu \mathrm{mol} / \mathrm{L}$ of DAPT, the cells started to show sub- $\mathrm{G}_{1}\left(\mathrm{M}_{1}\right)$ peaks, and 47.01\%, 44.24\% 32.55\% and $30.05 \%$ of total cells were observed in the apoptotic region after treatment with 10, 5.0, 2.0 and $1.0 \mu \mathrm{mol} / \mathrm{L}$ DAPT (Figures 2A, 2B, 2C, 2D), respectively. The induction of apoptosis was dosedependent and was found to be most pronounced at a concentration of $10 \mu \mathrm{mol} / \mathrm{L}$. Cells undergoing apoptosis displayed profound structural changes, including nuclear disintegration and membrane bleb formation.

\section{Effects of DAPT on Hes-1 and Notch-1 expre- ssions}

To examine the effect of DAPT on the expression of Hes-1, a target of Notch activation (Jarriault et al., 1998), we carried out a real-time PCR analysis. Hes-1 was constitutively expressed in freshly prepared Tca 8113 cells. A dose-dependent reduction in the levels of mRNA (Figure 3A) was observed in DAPT-treated cells. The mRNA levels of Notch-1 were also reduced by $40 \%-78 \%$ after DAPT treatment (Figure 3B), suggesting DAPT could both inhibit Notch activation and affect the expression levels of Notch-1 in Tca8113 cells.

\section{DAPT up-regulates Caspase-3 and down- regulates Bcl-1 expression}

As Caspase-3 and Bcl-1 play important roles in cell cycle arrest and apoptosis, we assayed the mRNA expression of Caspase-3 and Bcl-1 using real-time PCR to understand the molecular basis of the effects of DAPT. Consistent with the above results from FACS, cell cycle and apoptosis analysis, when the Tca8113 cells were treated with various concentrations of DAPT for 48 hours, the cellular mRNA level of Bcl-1 gradually decreased in a dose-dependent manner (Figure 3C). However, the mRNA level and immunoactivation of Caspase-3 

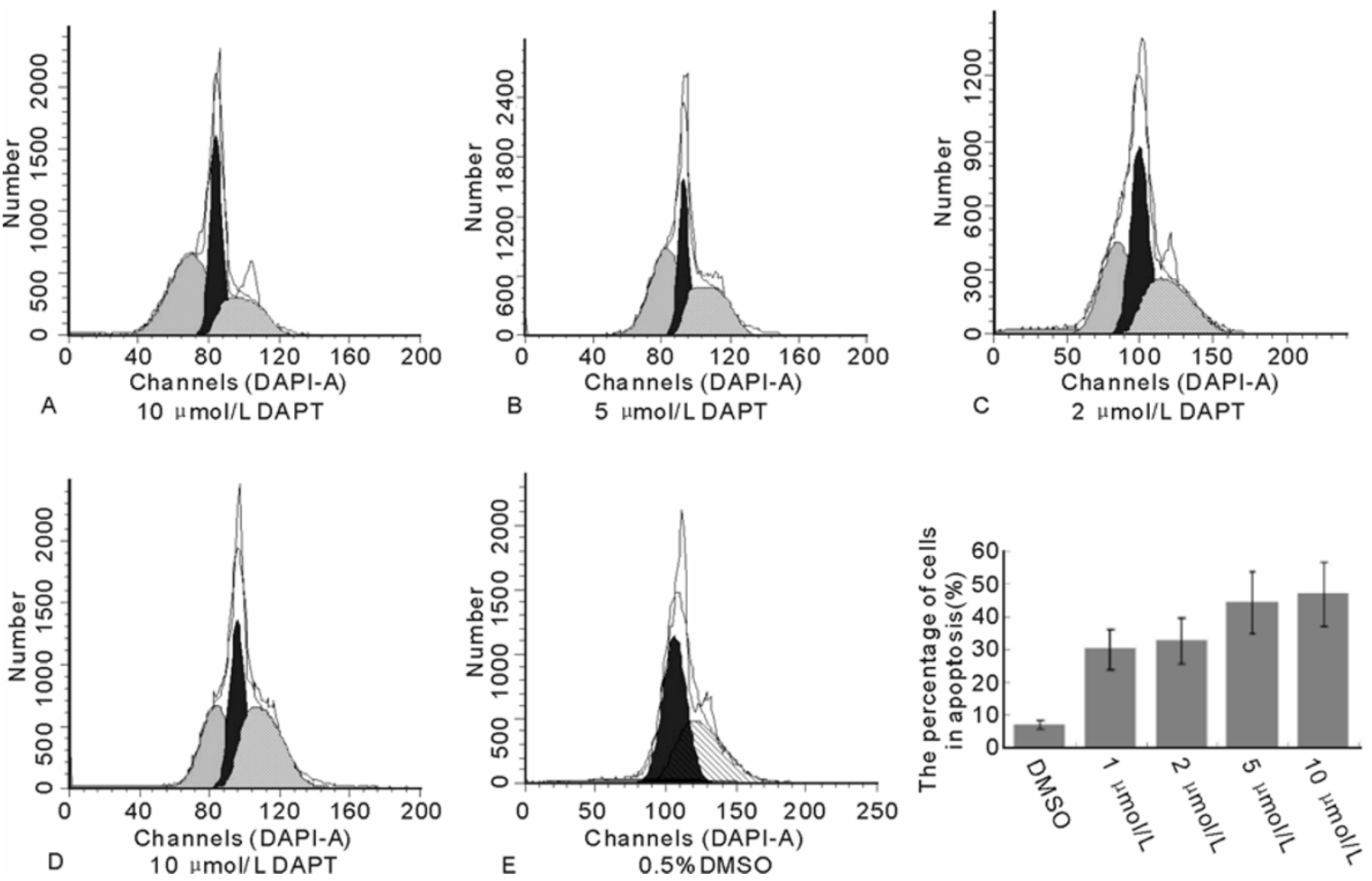

Figure 2 Effect of DAPT on cell cycle and apoptosis

Cells were treated with various concentrations of DAPT for 48 hours, and then analyzed using FACS. The results show $\mathrm{G}_{2} / \mathrm{G}_{1}$ and Total S phase (A-E), and data $(F)$ of percentages of cells in apoptosis showing the mean \pm S.D. from two independent experiments carried out in triplicate. A: Apoptosis $47.01 \%, \mathrm{G}_{2} / \mathrm{G}_{1}$ 1.48, Total S phase 39.68\%; B: Apoptosis 42.24\%, $\mathrm{G}_{2} / \mathrm{G}_{1} 1.44$, Total S phase $42.02 \%$; C: Apoptosis $32.55 \%$, $\mathrm{G}_{2} / \mathrm{G}_{1} 1.38$, Total S phase $46.73 \%$; D: Apoptosis $30.05 \%, \mathrm{G}_{2} / \mathrm{G}_{1} 1.29$, Total S phase $56.56 \%$; E: Apoptosis $7.03 \%, \mathrm{G}_{2} / \mathrm{G}_{1} 1.20$, Total $\mathrm{S}$ phase $65.10 \%$. There was a significant difference in apoptosis rate between the DAPT-treated group and the control group $(P<0.005)$.

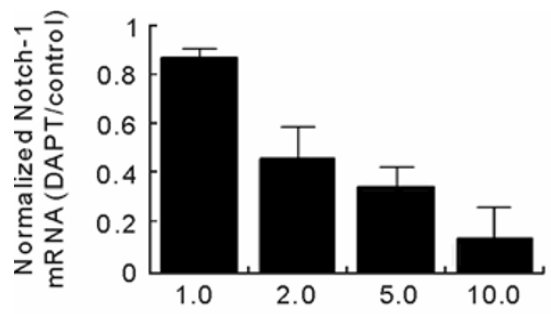

A DAPT concentration $(\mu \mathrm{mol} / \mathrm{L})$

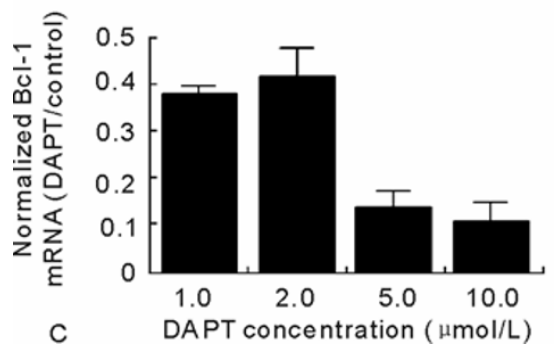

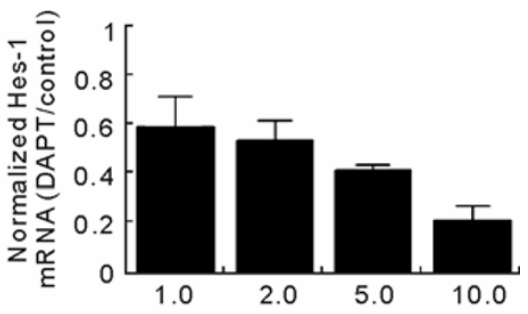

B DAPT concentration ( $\mu \mathrm{mol} / \mathrm{L}$ )

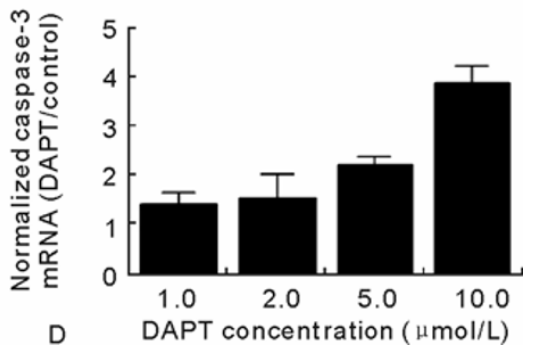

Figure 3 Effects of indicated concentration of DAPT ranging from 1.0 to $10.0 \mu \mathrm{mol} / \mathrm{L}$ on the mRNA expression of Notch-1, Hes-1, Bcl-1 and Caspase-3

The mRNA expression of these genes in Tca8113 cells was detected by real-time PCR analysis, and mRNA levels were normalized by control mRNA expression. Each DAPT concentration was tested in at least three independent experiments. There was a significant difference between each treated group and the control group $(0.5 \%$ DMSO $)(P<0.05)$. 

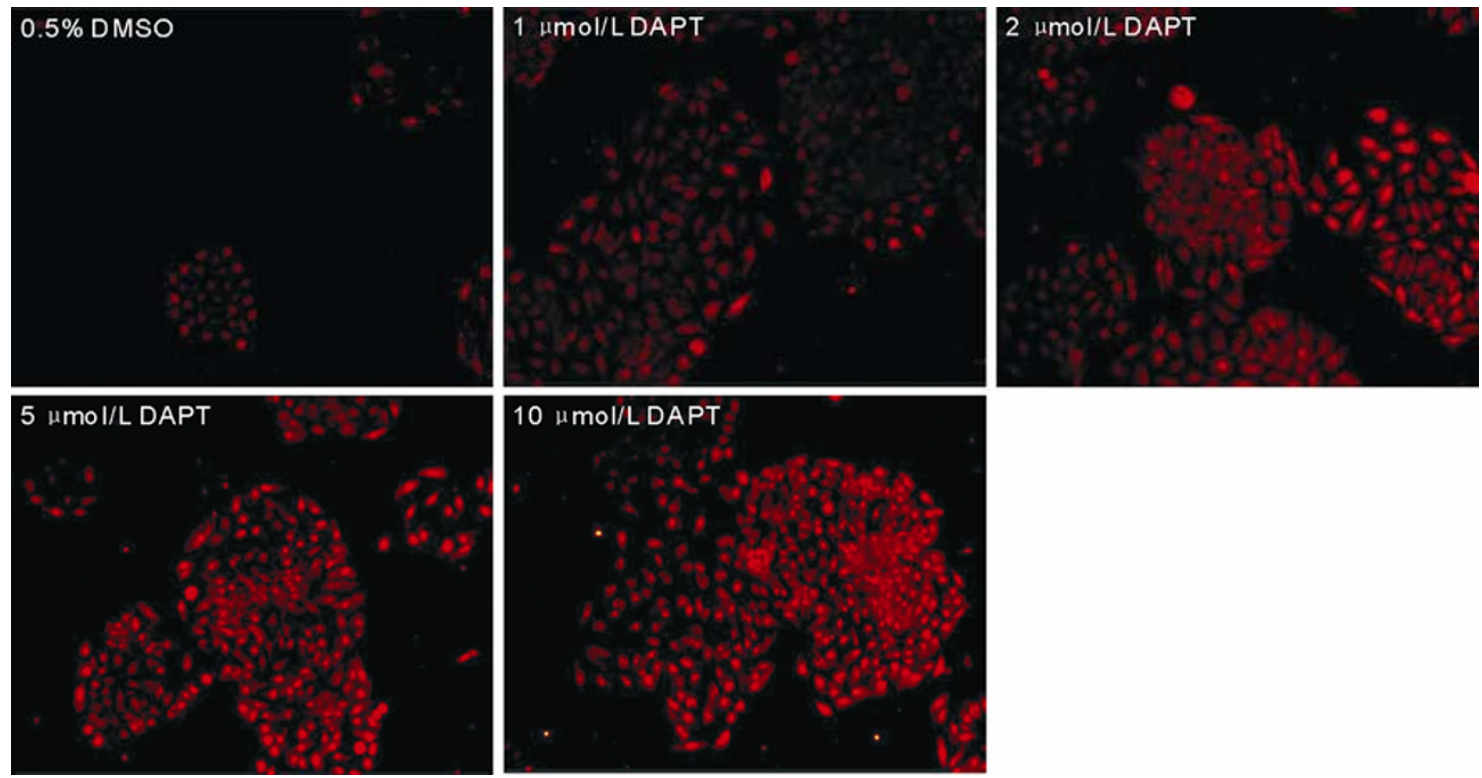

$10 \mu \mathrm{mol} / \mathrm{L}$ DAPT

Figure 4 Immunofluorescent detection of caspase-3 antigen in DAPT-treated Tca8113 cells

Immunoactivation of caspase- 3 in nuclei was significantly enhanced when the DAPT concentration was increased from 0 to $10 \mu \mathrm{mol} / \mathrm{L}$.

(Figure 3D and Figure 4) increased significantly in DAPT-treated cells. This suggests that downregulation of Bcl-1 expression and up-regulation of Caspase-3 might be involved in cell cycle arrest and apoptosis induced by DAPT.

\section{Discussion}

Activation of Notch-1 in mammalian epithelial carcinoma has been well studied in mouse models and human carcinoma (Farnie and Clarke, 2007; Yao et al., 2007; Liu et al., 2008). Not only is over-expression of Notch detected in some epithelial derived carcinoma such as mammary, prostate and so on, but truncated NICD protein can induce carcinogenesis in vitro (Capobianco et al., 1997). In mouse mammary epithelial cells, Notch-1, -3 and -4 block mammary gland development leading to mammary tumorigenesis. Although in human tongue cancer, the potential role of Notch is still unclear, activated Notch signaling may be common during tumorigenesis. To understand the biological function of Notch-1 in human oral squamous cell carcinoma, we examined the effects of Notch-1 inhibition on a human tongue cancer cell line, Tca8113 cells, using a GSI reagent, DAPT. Our results indicate that DAPT can induce cell cycle arrest and apoptosis. More importantly, we find that Caspase-3, a central apoptosis protein, is upregulated in Tca8113 cells.

Regulation of the cell cycle via Notch signalling involves the coordination of different, and sometimes antagonizing pathways in a highly cell contextdependent manner. In addition to its role in the cell cycle, Notch may play a role in apoptosis (Artavanis-Tsakonas et al., 1999).

Notch signalling has been implicated in tumorigenesis (Callahan and Raafat, 2001; Wu and Griffin, 2004; Axelson et al., 2006; Kimura et al., 2007), and Notch can either promote or suppress tumors depending on signalling strength, timing, cell type and context (Radtke and Raj, 2003; Lefort and Dotto, 2004). The Notch-1 signaling pathway plays a major role in maintaining the balance of cell proliferation, differentiation and apoptosis, and is closely associated with tumorigenesis. Aberrant increases in Notch-1 signalling are frequently present in colorectal carcinoma and a tendency for increased expression was observed when going from well to poorly differentiated carcinomas (Chu et al., 2008). A constitutively activated Notch-1 signaling pathway was observed in an esophageal squamous cell carcinoma (ESCC) cell line (Lu et al., 2008). The activated Notch-1 signaling pathway gave rise to proliferation suppression of the cells, accompanied by cell cycle inhibition at the $\mathrm{G}_{0} / \mathrm{G}_{1}$ phase and apoptosis. Furthermore, recent studies have shown 
that an antisense RNA or small interfering RNA (siRNA) approach for the inactivation of Notch-1 has a striking anti-neoplastic effect in vitro and in vivo (Weijzen et al., 2003), strongly supporting the potential role of Notch-1 as a novel therapeutic target for human malignancies. However, some studies suggest that activated Notch-1 and/or Notch-2 inhibit growth and induce cell cycle arrest in small-cell lung cancer (Sriuranpong et al., 2001) and hepatocellular carcinoma (Qi et al., 2003).

In this study, inhibition of cell growth observed using the Indigotic Reduction method suggested the induction of cell cycle arrest and/or apoptosis. Significantly, different concentrations of DAPT $(1.0-5.0 \mu \mathrm{mol} / \mathrm{L})$ were found to be effective in the suppression of cell growth, accompanied by cell cycle arrest and apoptosis, in a dose-dependent manner. However, when administered at a much higher concentration $(10.0 \mu \mathrm{mol} / \mathrm{L})$ (Figure 1), DAPT did not enhance cell growth suppression, cell cycle arrest and apoptotic activity. Furthermore, a marked reduction was observed in the levels of Bcl-1 expression in DAPT-treated cells, which was strongly correlated with the altered cell cycle distribution.

To explore the potential molecular mechanism by which DAPT results in the induction of apoptosis in Tca8113 cells, we further examined the expression of Caspase-3, a critical pro-apoptosis protein, and observed a marked increase in the levels of this protein in DAPT-treated cells. Activation of Caspase- 3 is a critical event during cell apoptosis, which can be activated by upstream signaling from, for example, Caspase-8 and -9 (Janicke, 2008). However, simultaneous deregulation of Caspase- 3 and -8 is a frequent event in tongue squamous cell carcinoma (Andressakis et al., 2008). Activation of Caspase-3, which is predominantly down-regulated, may be a crucial process for induction of apoptosis and response to therapeutic strategies. Because Caspase-3 can promote cells into apoptosis, our findings suggested that Caspase-3 overexpression and partial inactivation of Notch-1 appear to be relevant events that are somehow coupled to alterations in DAPT-treated Tca8113 cells.

More recent studies have indicated that GSIs, which attenuate Notch signalling, result in cell cycle arrest and/or apoptosis in carcinoma cells.
The GSI cbz-IL-CHO has Notch1-dependent antineoplastic activity in Ras-transformed fibroblasts (Weijzen et al., 2002). The GSI L-685, 458 can dose-dependently inhibit the growth of human tongue carcinoma cells by inducing $\mathrm{G}_{0}-\mathrm{G}_{1}$ cell cycle arrest and apoptosis (Yao et al., 2007). However, the exact mechanism of action of GSIs in the Tca8113 cells has not been exactly revealed. Further studies are in progress to investigate the additional antiproliferative and antitumor mechanisms of novel $\gamma$-secretase inhibitors in in vitro and in vivo experimental systems for devising novel preventive and therapeutic strategies for human tongue carcinoma.

\section{Conclusion}

In summary, our studies show that DAPT inhibits the growth of human tongue carcinoma cells by inducing cell cycle arrest and apoptosis, with reduced levels of proteins Hes- 1 and Bcl-1, and increased constitutive expression of Caspase- 3 . These results may suggest a novel chemical class of antitumor agents targeting Notch functionality, and also indicate the possible mechanism of action of this type of compound in the control of tongue carcinoma cell growth. Further in-depth experiments are needed to investigate the precise molecular mechanisms with regard to the cause and effect relationship between Notch-1 and Caspase-3 in oral squamous cell carcinoma.

\section{Acknowledgements}

This work was funded by the National Natural Science Foundation of China (30801304), Specialized Research Fund for the Doctoral Program of Higher Education (20070610062), Opening Funding of the State Key Laboratory of Oral Diseases, Sichuan University (SKLOD011) and the Applied Fundarmental Project of Sichuan Province (2008 JY0028-2).

\section{References}

Andressakis D, Lazaris AC, Tsiambas E, Kavantzas N, Rapidis A, Patsouris E (2008). Evaluation of caspase-3 
and caspase- 8 deregulation in tongue squamous cell carcinoma, based on immunohistochemistry and computerised image analysis. J Laryngol Otol, 122(11): 1213-1218.

Artavanis-Tsakonas S, Rand MD, Lake RJ (1999). Notch signaling: cell fate control and signal integration in development. Science, 284(5415): 770-776.

Axelson H (2006). Eyeing tumorigenesis: Notch signaling and epigenetic silencing of $\mathrm{Rb}$ in Drosophila. Bioessays, 28(7): 692-695.

Baldi A, De Falco M, De Luca L, Cottone G, Paggi MG, Nickoloff BJ, et al. (2004). Characterization of tissue specific expression of Notch-1 in human tissues. Biol Cell, 96(4): 303-311.

Baron M (2003). An overview of the Notch signalling pathway. Semin Cell Dev Biol, 14(2): 113-119.

Callahan R, Egan SE (2004). Notch signaling in mammary development and oncogenesis. J Mammary Gland Biol Neoplasia, 9(2): 145-163.

Callahan R, Raafat A (2001). Notch signaling in mammary gland tumorigenesis. J Mammary Gland Biol Neoplasia, 6(1): 23-36.

Capobianco AJ, Zagouras P, Blaumueller CM, ArtavanisTsa-konas S, Bishop JM (1997). Neoplastic transformation by truncated alleles of human NOTCH1/TAN1 and NOTCH2. Mol Cell Biol, 17(11): 6265-6273.

Cheng HT, Kopan R (2005). The role of Notch signaling in specification of podocyte and proximal tubules within the developing mouse kidney. Kidney Int, 68(5): 19511952.

Chu D, Wang W, Xie H, Li Y, Dong G, Xu C, et al. (2009). Notch1 expression in colorectal carcinoma determines tumor differentiation status. J Gastrointest Surg, 13(2): 253-260.

Fan X, Mikolaenko I, Elhassan I, Ni X, Wang Y, Ball D, et al. (2004). Notch1 and notch2 have opposite effects on embryonal brain tumor growth. Cancer Res, 64(21): 7787-7793.

Farnie G, Clarke RB (2007). Mammary stem cells and breast cancer-role of Notch signalling. Stem Cell Rev, 3(2): 169-175.

Grabher C, von Boehmer H, Look AT (2006). Notch 1 activation in the molecular pathogenesis of T-cell acute lymphoblastic leukaemia. Nat Rev Cancer, 6(5): 347359.

Hansson EM, Lendahl U, Chapman G (2004). Notch signaling in development and disease. Semin Cancer Biol, 14(5): 320- 328 .

Hartmann T, Bieger SC, Brühl B, Tienari PJ, Ida N, Allsop $\mathrm{D}$, et al. (1997). Distinct sites of intracellular production for Alzheimer's disease A beta40/42 amyloid peptides. Nat Med, 3(9): 1016-1020.

Imatani A, Callahan R (2000). Identification of a novel NOTCH-4/INT-3 RNA species encoding an activated gene product in certain human tumor cell lines. Oncogene, 19(2): 223-231.

Iso T, Kedes L, Hamamori Y (2003). HES and HERP families: multiple effectors of the Notch signaling pathway. J Cell Physiol, 194(3): 237-255.

Iso T, Sartorelli V, Chung G, Shichinohe T, Kedes L, Hamamori Y (2001). HERP, a new primary target of Notch regulated by ligand binding. Mol Cell Biol, 21(17): 6071-6079.

Janicke RU (2008). MCF-7 breast carcinoma cells do not express caspase-3. Breast Cancer Res Treat, [Epub ahead of print].

Jorgensen C, Leser TD (2007). Estimating amplification efficiency improves multiplex real-time PCR quantification of Bacillus licheniformis and Bacillus subtilis spores in animal feed. $J$ Microbiol Methods, 68(3): 588-595.

Joshi I, Minter LM, Telfer J, Demarest RM, Capobianco AJ, Aster JC, et al. (2009). Notch signaling mediates G1/S cell cycle progression in T cells via cyclin D3 and its dependent kinases. Blood, 113(8): 1689-1698.

Kadesch T (2004). Notch signaling: the demise of elegant simplicity. Curr Opin Genet Dev, 14(5): 506-512.

Katoh M, Katoh M (2007). Notch signaling in gastrointestinal tract (review). Int J Oncol, 30(1): 247-251.

Kimura K, Satoh K, Kanno A, Hamada S, Hirota M, Endoh $\mathrm{M}$, et al. (2007). Activation of Notch signaling in tumorigenesis of experimental pancreatic cancer induced by dimethylbenzanthracene in mice. Cancer Sci, 98(2): 155-162.

Lefort K, Dotto G.P (2004). Notch signaling in the integrated control of keratinocyte growth/differentiation and tumor suppression. Semin Cancer Biol, 14(5): 374-386.

Liao WR, Hsieh RH, Hsu KW, Wu MZ, Tseng MJ, Mai RT, et al. (2007). The CBF1-independent Notch1 signal pathway activates human c-myc expression partially via transcription factor YY1. Carcinogenesis, 28(9): 1867-1876.

Liu ZL, Li Y, Kong QY, Zhan C, Wang Q, Chen XY, et al. (2008). Immunohistochemical profiling of Wnt, NFkappaB, Stat3 and Notch signaling in human epidermal tumors. J Dermatol Sci, 52(2): 133-136.

Lovschall H, Tummers M, Thesleff I, Füchtbauer EM, Poulsen K (2005). Activation of the Notch signaling pathway in response to pulp capping of rat molars. Eur J Oral Sci, 113(4): 312-317.

Lu Z, Liu H, Xue L, Xu P, Gong T, Hou G (2008). An 
Grottkau et al. DAPT Enhances Tongue Carcinoma Cells Apoptosis

activated Notch1 signaling pathway inhibits cell proliferation and induces apoptosis in human esophageal squamous cell carcinoma cell line EC9706. Int $J$ Oncol, 32(3): 643-651.

Maliekal TT, Bajaj J, Giri V, Subramanyam D, Krishna S (2008). The role of Notch signaling in human cervical cancer: implications for solid tumors. Oncogene, 27(38): 5110-5114.

Mansour MR, Linch DC, Foroni L, Goldstone AH, Gale RE (2006). High incidence of Notch-1 mutations in adult patients with T-cell acute lymphoblastic leukemia. Leukemia, 20(3): 537-539.

McKenzie RC, Sabin E (2003). Aberrant signalling and transcription factor activation as an explanation for the defective growth control and differentiation of keratinocytes in psoriasis: a hypothesis. Exp Dermatol, 12(4): 337-345.

Mitsiadis TA, Regaudiat L, Gridley T (2005). Role of the Notch signalling pathway in tooth morphogenesis. Arch Oral Biol, 50(2): 137-140.

Nickoloff BJ, Osborne BA, Miele L (2003). Notch signaling as a therapeutic target in cancer: a new approach to the development of cell fate modifying agents. Oncogene, 22(42): 6598-6608.

Ohazama A, Hu Y, Schmidt-Ullrich R, Cao Y, Scheidereit C, Karin M, et al. (2004). A dual role for Ikk alpha in tooth development. Dev Cell, 6(2): 219-227.

O'Neill CF, Urs S, Cinelli C, Lincoln A, Nadeau RJ, León $\mathrm{R}$, et al. (2007). Notch2 signaling induces apoptosis and inhibits human MDA-MB-231 xenograft growth. Am J Pathol, 171(3): 1023-1036.

Paris D, Quadros A, Patel N, DelleDonne A, Humphrey J, Mullan M (2005). Inhibition of angiogenesis and tumor growth by beta and gamma-secretase inhibitors. Eur J Pharmacol, 514(1): 1-15.

Qi R, An H, Yu Y, Zhang M, Liu S, Xu H, et al. (2003). Notch1 signaling inhibits growth of human hepatocellular carcinoma through induction of cell cycle arrest and apoptosis. Cancer Res, 63(23): 8323-8329.
Radtke F, Raj K (2003). The role of Notch in tumorigenesis: oncogene or tumour suppressor? Nat Rev Cancer, 3(10): 756-767.

Sriuranpong V, Borges MW, Ravi RK, Arnold DR, Nelkin BD, Baylin SB, et al. (2001). Notch signaling induces cell cycle arrest in small cell lung cancer cells. Cancer Res, 61(7): 3200-3205.

Talora C, Campese AF, Bellavia D, Felli MP, Vacca A, Gulino A, et al. (2008). Notch signaling and diseases: an evolutionary journey from a simple beginning to complex outcomes. Biochim Biophys Acta, 1782(9): 489-497.

Vacca A, Felli MP, Palermo R, Di Mario G, Calce A, Di Giovine M, et al. (2006). Notch3 and pre-TCR interaction unveils distinct NF-kappaB pathways in T-cell development and leukemia. Embo J, 25(5): 1000-1008.

Weijzen S, Rizzo P, Braid M, Vaishnav R, Jonkheer SM, Zlobin A, et al. (2002). Activation of Notch-1 signaling maintains the neoplastic phenotype in human Ras-transformed cells. Nat Med, 8(9): 979-986.

Weijzen S, Zlobin A, Braid M, Miele L, Kast WM (2003). HPV16 E6 and E7 oncoproteins regulate Notch-1 expression and cooperate to induce transformation. $J$ Cell Physiol, 194(3): 356-362.

Wu L, Griffin JD (2004). Modulation of Notch signaling by mastermind-like (MAML) transcriptional co-activators and their involvement in tumorigenesis. Semin Cancer Biol, 14(5): 348-356.

Yao J, Duan L, Fan M, Yuan J, Wu X (2007). Notch1 induces cell cycle arrest and apoptosis in human cervical cancer cells: involvement of nuclear factor kappa B inhibition. Int J Gynecol Cancer, 17(2): 502510.

Zhu YM, Zhao WL, Fu JF, Shi JY, Pan Q, Hu J, et al. (2006). NOTCH1 mutations in T-cell acute lymphoblastic leukemia: prognostic significance and implication in multifactorial leukemogenesis. Clin Cancer Res, 12(10): 3043-3049.

\footnotetext{
*Corresponding authors:

Yun-feng Lin
}

Address: State Key Laboratory of Oral Disease, West China College of Stomatology, Sichuan University, No. 14, $3^{\text {rd }}$ Section, Renmin South Road, Chengdu, 610041, China

Tel: 862885503406 Fax: 862885582167 E-mail: yunfenglin@scu.edu.cn

Yuan-ding Huang

Address: Department of Oral and Maxillofacial Surgery, Beijing Friendship Hospital affiliated to Capital Medicine University, Beijing, China

Tel: $861063138416 \quad$ Fax: $861063023261 \quad$ Email: huangyd@126.com 